purify and fold the proteins produced.

We have been producing Arg 52-BPTI, with methionine 52 replaced by arginine, as a fusion protein, releasing the BPTI moiety by cyanogen bromide cleavage at a preceding methionine residue, and purifying it in the reduced unfolded form. Our initial product appeared to be authentic and nearly pure, but precipitated in conditions conducive to disulphide bond formation and folding. At lower concentrations, the protein remained soluble but formed intermolecular mixed disulphide bonds rather than the correct intramolecular protein disulphide bonds. This behaviour was surprising; the folding behaviour of normal BPTI is well characterized ${ }^{2}$ and we used conditions that normally produce quantitative refolding. The substitution of methionine 52 by arginine seemed an unlikely explanation.

A more plausible explanation is that the recombinant BPTI is isolated as a complex with some other tightly-bound substance that markedly affects it solubility and folding properties. BPTI is a very basic protein, whereas most intracellular macromolecules are acidic, so that the most likely candidate for a complexing partner would be a polyanion. Such an electrostatic complex might be most readily resolved by ion-exchange chromatography at extremes of $\mathrm{pH}$, where the net charge on one component would be minimal. In accordance with this expectation, recombinant BPTI purified on a cation exchange resin at $\mathrm{pH} 2$ was found to have the solubility and folding properties of normal BPTI. Our treatment seems to have removed an acidic component not yet identified. Another recent study ${ }^{3}$ has also demonstrated that the treatment of recombinant proteins with ion-exchange resins improves their solubility, but does not propose an explanation.

These observations suggest that inclusion body formation may sometimes occur because the newly synthesized polypeptide chain forms a tight complex with a component of the foreign cell in which it is synthesized, with unfavourable consequences for its solubility and folding properties. A variety of interactions may stabilize such complexes, so that there can be no general rules for dissociating them. Nevertheless, awareness of the possible presence of complexes should suggest ways of resolving them as well as the stage in the purification process at which refolding of the protein should be attempted.

NIGEL J. DARBY ThOMASE. CREIGHTON MRC Laboratory of Molecular Biology, Hills Road, Cambridge CB2 2QH, UK

1. Marston, F.A.O. Biochem. J. 240, 1-12 (1986).

2. Creighton, T.E. Prog. Biophys. molec. Biol. 33, 231-297 (1978).

3. Hoess, A., Arthur, A.K., Wanner, G. \& Fanning, E. Bio/ Technology 6, 1214-1217 (1988)

\title{
Swallowtail performance
}

SIR-The claim ${ }^{1}$ that genes for oviposition preference and genes for larval performance are not linked in the host specific swallowtail butterflies Papilio zelicaon and $P$. oregonius would have important implications for the evolution of phytophagous insects. But the conclusion seems to be premature.

Oviposition preference in these species is controlled by genes on the X chromosome $^{2}$, which is why Thompson et al. ${ }^{1}$ sought evidence that larval performance is also sex-linked. Since females are heterogametic in butterflies, sex linkage predicts that female F1 hybrid larvae should perform like their male parents. There is clear evidence from survivorship of larvae that $P$. zelicaon and $P$. oregonius perform better on their own host plants, but survival could not be used to test sex linkage because male and female larvae could not be distinguished. Two other measures of larval performance were used instead development time and pupal mass of surviving larvae - that could be measured on the two sexes separately. No evidence for sex linkage was found.

The problem with these two measures of performance is that they do not appear to be good indicators of adaptation to the host plants. For both measures, $P$. zelicaon has a lower score than $P$. oregonius on both hosts. The difference is somewhat greater on the natural host of $P$. oregonius, but this effect is slight and no significant host/species interaction is quoted by the authors. If the characters scored are not good measures of adaptation to alternative hosts, then the absence of sex linkage is irrelevant to the question of genetic linkage between oviposition preference and larval performance.

ROGER BUTLIN Department of Pure and Applied Biology, University of Wales College of Cardiff, PO Box 915,

Cardiff CF1 $3 T L$, UK

\footnotetext{
1. Thompson, J.N., Wehling, W. \& Podolsky, R. Nature 344, $148-150(1990)$

2. Thompson, J.N. Evolution 42, 1223-1234 (1988).
}

\section{Glucose in glucagon release}

SIR - We read with interest the contribution to Scientific Correspondence by Gylfe $^{1}$ concerning our recent Letter ${ }^{2}$. The concept that glucose lowers $\left[\mathrm{Ca}^{2+}\right]_{i}$ has recently been proposed by Gylfe and co-workers to be the mechanism by which the sugar inhibits glucagon release ${ }^{3,4}$. Although we cannot disregard such a mechanism, the existing experimental support is insufficient. First, all experiments were performed on cells at a basal glucose concentration of $0 \mathrm{mM}$, suggesting that the alpha ${ }_{2}$ cells were deprived of fuel. Consequently, when the glucose concentration was restored to physiological resting levels (about $5 \mathrm{mM}$ ) the ATPdependent $\mathrm{Ca}^{2+}$ pumps can be expected to be activated with a resultant lowering in $\left[\mathrm{Ca}^{2+}\right]_{\mathrm{i}}$. Second, Gylfe and co-workers have not shown that glucagon is present in the cells subjected to $\left[\mathrm{Ca}^{2+}\right]_{\mathrm{i}}$ measurements. Finally, in their studies, changes in $\left[\mathrm{Ca}^{2+}\right]_{\mathrm{i}}$ were not correlated to glucagon release.

For the neurotransmitter GABA cosecreted with insulin to be an effective regulator of glucagon release, it should have a pronounced effect already in the early phase of insulin release. Gerich et al. ${ }^{5}$ found an increase in insulin and thereby GABA release at about $2.5 \mathrm{mM}$ glucose, consistent with the idea that GABA inhibits glucagon release. Further, as we pointed out ${ }^{2}$, the $\mathrm{GABA}_{\mathrm{A}}$-receptor antagonist bicuculline counteracts the inhibitory effect of glucose on glucagon release. These data, together with the observation of glucagon hypersecretion in non-insulin-dependent diabetes mellitus, support our hypothesis ${ }^{2}$.
Although our hypothesis does not exclude other mechanisms by which glucose may inhibit or modulate glucagon release, it is probably the chief mode of action of the sugar. Indeed, it is of interest that a second level of glucose control of glucagon release may be possible by direct metabolic modulation of the $\mathrm{GABA}_{\mathrm{A}}$ receptor, as has been recently demonstrated ${ }^{6}$ in dissociated mouse neurons.

With respect to citation, we did not state that Okada et $a .^{7}$ were the first to demonstrate GABA within the pancreatic islets. That GABA is present in the endocrine part of the pancreas at concentrations comparable to those encountered in the central nervous system, however, is highly relevant to the credibility of our hypothesis.

Department of Medical Physics,

Gothenburg University,

Box 33031, S-400 33 Gothenburg,

Sweden

Department of Endocrinology,

Karolinska Institute,

Box 60500, S-104 01 Stockholm,

Sweden

University Laboratory of Physiology,

Parks Road, Oxford OX1 3PT, UK

1. Gylfe, E. Nature 344, 300 (1990).

2. Rorsman, P. et al. Nature 341, 233-236 (1989).

3. Johansson, H., Gylfe, E. \& Hellman, B. Biochem. biophys. Res. Commun. 147, 309-314 (1987)

4. Johannson, H., Gylfe, E. \& Hellman, B. Cell Calcium 10 205-211 (1989).

5. Gerich, J.E. et al. A. Rev. Physiol. 38, 353 (1976).

6. Duchen, M.R. J. Physiol. 415, 48 (1989).

7. Okada, Y., Tamgusti, H. \& Shimada, C. Science 194, $620-622$ (1979). 